BENHA VETERINARY MEDICAL JOURNAL, VOL36, No.1, 252 -261, MARCH, 2019

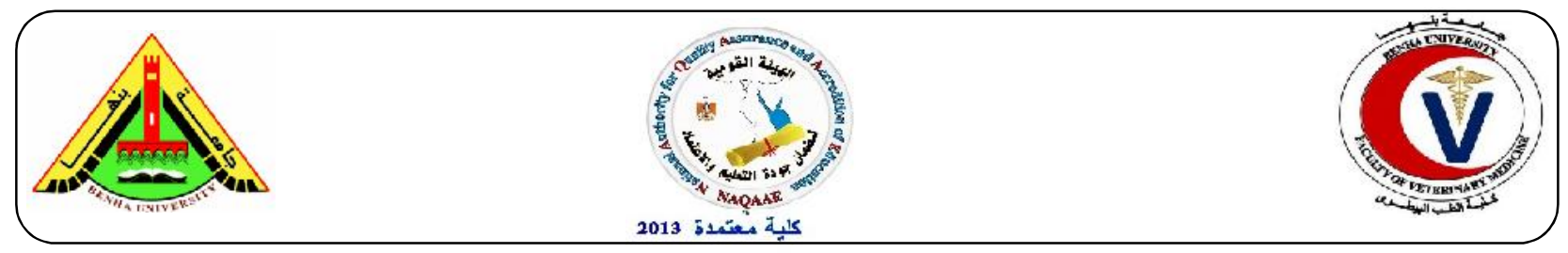

\title{
Antioxidants and hepatoprotective effects of chitosan nanoparticles against hepatotoxicity induced in rats
}

\author{
Omayma A.R.Abou zaid ${ }^{1}$; Sawsan M.Elsonbaty ${ }^{2}$; Fatma S.Moawad ${ }^{3}$ and Mostafa, M.Abdelghaffar ${ }^{1}$. \\ ${ }^{1}$ Clinical Biochemistry Dep. Faculty of Veterinary Medicine, Benha University. \\ ${ }^{2}$ Radiation Microbiology Dep. The National Center for Radiation Research and Technology,Atomic Energy Authority. \\ ${ }^{3}$ Health Radiation Research Dep. The National Center for Radiation Research and Technology, Atomic Energy Authority.
}

\section{A B S T R A C T}

This study was conducted to investigate the preventive effects of Chitosan-nanoparticles on diethylnitrosamine (DEN) induced hepatotoxicity in albino rats. Forty male albino rats were divided into four groups: group (1): normal control, group (2): group (2): hepatotoxic rats administrated DEN orally (20 mg/kg b.wt/ day), group (3): rats receive chitosan-nanoparticles orally and group (4): Hepatotoxic rats were treated with chitosan-nanoparticles orally at a dose of (200 mg / kg bw/day). All animals were sacrificed at the end of experiment (12 weeks). The hepatotoxic effect of DEN was evidenced by elevation of serum Aspartate Aminotransferase, Alanine Aminotransferase, Alkaline Phosphatase, $\gamma$-Glutamyl transferase activities, blood Urea concentration and liver Malondialdehyde level. However serum albumin concentration and antioxidants biomarkers in liver tissue were markedly decreased. In conclusion, the administration of chitosan nanoparticles restored the DEN induced alterations in liver functions, promoted oxidative stress and antioxidant defense

Key words: Diethylnitrosoamine, hepatotoxicity, Chitosan nanoparticles, oxidative stress.

(http://www.bvmj.bu.edu.eg)

(BVMJ-36(1): 252-261, 2019)

\section{INTRODUCTION}

The liver is a vital organ and its strategic location and multidimensional functions support almost every other organ in the body. Liver is also the main organ for metabolism and elimination of drugs (Singh et al., 2012). Hepatitis is caused due to viruses, poisons, autoimmunity and can also result from non-alcoholic fatty liver disease connected with obesity and steatosis. Hepatic encephalopathy is caused by accumulation of toxins in the bloodstream that are normally removed by the liver. Liver damage can also be caused by drugs, particularly anti-tubercular drugs, general anesthetics, paracetamol and some anti-cancer drugs. Toxic hepatitis is the most severe adverse reaction to antituberculosis drugs, it usually initiates in the first few weeks of treatment along with liver necrosis, which may evolve to encephalopathy and death. Alcoholic liver diseases with cirrhosis (formation of fibrous tissue in liver) caused by excessive alcohol consumption is a common occurrence. Liver can sometimes be damaged by some chemicals called hepatotoxins, such as galactosamine and 
chloroform (Mohan, 2002). Moreover, steroids, vaccines and antiviral drugs which are used as therapy for liver diseases, may produce adverse effects especially after chronic administration. There are more than 900 drugs that can lead to hepatotoxicity and is one of the important reasons for some of the drugs withdrawn from market. Liver toxicity not only occurs from direct toxicity of the primary compound but also from reactive metabolite or immunologicallymediated response. This can affect hepatocytes, biliary epithelial cells and liver vasculature (Singh et al., 2011; Deng et al., 2009).

Diethylnitrosamine (DEN) is found in a wide variety of foods such as cheese, soybeans, smoked, salted and dried fish, cured meat and alcoholic beverages (Liao et al., 2001). It is reported to be metabolically activated by cytochrome $\mathrm{P} 450$ enzymes to form reactive electrophiles which induce oxidative stress leading to cytotoxicity, mutagenicity and carcinogenicity (Bleibel et al., 2007). Oxidative stress is considered essential to DEN induced hepatotoxicity and the use of antioxidant agents reduced liver damage (Vitaglione et al., 2004; Pradeep et al., 2007).

Chitosan, an important polysaccharide of marine origin, is prepared from the shells of crustaceans. It has attracted much attention as a biomedical material, owing to its antitumor (Qi and $\mathrm{Xu}$, 2006), antiulcer, immunostimulatory (Neimert et al., 2011), and antibacterial activities (No et al., 2002). In recent years, the antioxidant activity of chitosan has attracted the most attention. Studies show that chitosan has hepatoprotective effects related to antioxidant activity (Jeon et al., 2003). Chitosan, the deacetylated product of chitin, is a natural polysaccharide with a great potential to be a substitute for synthetic stabilizers. Chitosan consists of glucosamine and $\mathrm{N}$-acetyl glucosamine units linked together by $\beta-1,4-$ glucosidic bonds. Chitosan shows unique polycationic, chelating and film forming properties as it is an oxygen rich linear polysaccharide having active amino and hydroxyl groups (Nguyen et al. 2009). Therefore, chitosan exhibits a number of interesting biological activities such as biocompatibility, biodegradability, non-toxicity, non-antigenicity and adsorption properties.

The present study aimed to investigate the potential effects of chitosan-nanoparticles on hepatic toxicity induced by DEN in rats.

\section{MATERIAL AND METHODS}

2.1. Experimental animals:

Forty white male albino rats of 4 - 6 weeks old and weighing (100-120) g were used in this study. Rats were obtained from "The Laboratory Animals Research Center", Faculty of Veterinary Medicine, Benha University.

Animals were housed in separate metal cages, exposed to good ventilation, humidity and to a 12-hr light/dark cycle. All rats were acclimatized for a period of 15 days prior to the beginning of the experiment. The rats were fed on constant supplies of standard pellet diet, fresh and clean drinking water were supplied ad-libitum.

2.2. Chemicals and Chitosan:

a) Diethylnitrosamine (DEN) was purchased from Sigma chemical Co. (USA). DEN was prepared freshly in normal saline $(20 \mathrm{mg} / \mathrm{kg} \mathrm{b.wt} /$ day). Rats were received ( $1 \mathrm{ml} / \mathrm{kg}$ b.wt) 5 days per week till the end of the experimental periods (12 weeks), according to (El-Shahat et al., 2012).

b) Chitosan nanoparticles:

Chitosan was purchased from Techno-Gen, Giza, Egypt, treated orally with a dose of (200 mg / 1 kg b.wt/ day) (Sugiyama et al., 1999).

c) Preparation of Chitosan nanoparticles: 
Chitosan $(2 \mathrm{mg} / \mathrm{ml})$ was dissolved in $10 \mathrm{ml}$ of acetic acid aqueous solution ( $1 \%$ and $0.2 \% \mathrm{v} / \mathrm{v})$ and Tripolyphosphate (TPP) $(1.2 \mathrm{mg} / \mathrm{ml})$ was dissolved in purified water. The TPP solution was added to the polymer solution during magnetic stirring (500 rpm) at room temperature, spontaneously forming an opalescent suspension. The resulting product was exhaustively dialyzed against triple distilled water and then freezedried for $48 \mathrm{~h}$. The chemical structure of LC was analyzed using a Fourier transform infrared (FTIR) and ${ }^{1} \mathrm{H}$ nuclear magnetic resonance $\left({ }^{1} \mathrm{H}\right.$ NMR) spectroscopy (Wang et al., 2010).

2.3. Experimental design and sample collection: Rats were randomly divided into four groups each of them comprises of (10) rats:

Group (1): (Normal Control), rats received no drugs treatment during the experimental periods (12 weeks).

Group (2): (DEN-induced hepatotoxic group), rats were received Diethylnitrosamine (DEN) in normal saline at a dose level of $(20 \mathrm{mg} / \mathrm{kg}$ b.wt/ day) orally. Rats were received ( $1 \mathrm{ml} / \mathrm{kg} \mathrm{b.wt)} 5$ days per week till the end of the experimental periods (12 weeks).

Group (3): (Chitosan nanoparticles treated), rats were administrated with chitosan nanoparticles orally at a dose of (200 mg $/ \mathrm{kg} \mathrm{b.wt/} \mathrm{day).} \mathrm{Rats}$ were received $(1 \mathrm{ml} / \mathrm{kg} \quad$ b.wt $)$ of chitosan nanoparticles 5 days per week till the end of the experimental periods (12 weeks).

Group (4): (DEN+ Chitosan nanoparticles treated), rats were administrated with Diethylnitrosamine (DEN) in normal saline (20 $\mathrm{mg} / \mathrm{kg} \mathrm{b.wt/day)} \mathrm{till} \mathrm{the} \mathrm{end} \mathrm{of} \mathrm{induction} \mathrm{period}$ of hepatotoxicity ( 8 weeks) then treated with chitosan nanoparticles orally at a dose of $(800 \mathrm{mg}$ / kg bw/day). Rats were received ( $1 \mathrm{ml} / \mathrm{kg} \mathrm{b.wt)}$ of chitosan nanoparticles 5 days per week till the end of the treatment period (4 weeks).

\subsection{Sampling:}

2.4.1. Blood samples:

Twenty-four hours fasting after the last dose of the drugs administration, rats were anaesthetized under diethyl ether anesthesia. Blood samples were collected by ocular vein puncture in dry, clean tubes and allowed to clot for 30 minutes and serum was separated by centrifugation at 3000 r.p.m for 15 minute. The serum was taken by automatic pipettes and collected in dry sterile tubes, then kept in deep freeze at $-20{ }^{\circ} \mathrm{C}$ until use for assay of the liver biomarker. All sera were analyzed for determination of the following parameters: Urea, AST, ALT, albumin, GGT and Alkaline Phosphatase.

\subsubsection{Liver tissue for biochemical analysis:}

Briefly, liver tissues were cut, weighed and minced into small pieces, about $0.5 \mathrm{~g}$ of liver tissues were collected from all animals groups (control and experimental groups), put in Eppendorf tubes and were immediately kept at $20^{\circ} \mathrm{C}$ till for subsequent biochemical analyses.

\subsubsection{Preparation of liver homogenates:}

1. Prior to dissection, perfuse liver tissues with a PBS (phosphate buffered saline) solution, $\mathrm{pH} 7.4$ containing $0.16 \mathrm{mg} / \mathrm{ml}$ heparin to remove any red blood cells and clots.

2. Liver tissues were divided into appropriate portions, and $0.5 \mathrm{gm}$ from each were homogenized in 5 ml -10\% (w/v)- cold phosphate buffer saline (PBS) (i.e., $50 \mathrm{mM}$ potassium phosphate, $\mathrm{PH} 7.5,0.1 \mathrm{mM}$ EDTA) per gram tissue, using tissue homogenizer.

3. Centrifuged at 10,000 r.p.m for 20 minutes at $4^{\circ} \mathrm{C}$, the resulting supernatant was assayed for: Oxidative stress and antioxidant biomarkers: L-MDA, reduced glutathione, Superoxide dismutase and Catalase. 


\subsection{Biochemical analysis}

Serum aspartate aminotransferase (AST), Serum alanine aminotransferase (ALT), Serum albumin, Serum $\gamma$-GT, Serum Alkaline Phosphatase and Serum Urea levels were determined according to the methods described by (Murray, 1984), (Doumas et al., 1997), (Beleta and Gella, 1990), (Rosalki et al., 1993) and (Palton and Crouch, 1977) respectively.Moreover, liver L-MDA, reduced glutathione, superoxide dismutase, Catalase levels were determined in liver tissue homogenate according to the method described by (Esterbauer et al., 1982), (Beutler et al., 1963), (Minami \& Yoshikawa, 1979) and (Sinha, 1972). 3. Statistical analysis

Experimental data obtained were analyzed according to (Snedecor and Cochran, 1969) using the computer software program (SPSS, 2001).

\section{RESULTS}

The obtained results demonstrated in (table 1) revealed that, DEN hepatotoxicity in rats induced a significant increase in serum liver marker enzymes, GGT, Alkaline Phosphatase, Urea and liver L-MDA as compared to normal control group. Oral administration of chitosan nanoparticles caused a significant reduction in all of those parameters when compared with DEN exposed group with the ability to restore the enzymatic activities to the normal level of control group. On the other hand, Hepatotoxicity induced a significant decrease in serum albumin level, GSH, SOD and Catalase in liver tissue as compared with normal control group.Chitosan nanoparticles administration restored the DEN induced biochemical alterations in serum liver function tests and promoted oxidative stress and antioxidant defense in the liver tissue.

Table 1: Effect of chitosan nanoparticles administration on Serum biochemical parameters in blood and liver tissue of DEN induced hepatotoxicity in rats.

\begin{tabular}{crrrr}
\hline Parameter & \multicolumn{4}{c}{ Groups } \\
\cline { 2 - 5 } & \multicolumn{1}{c}{ G1 } & \multicolumn{1}{c}{ G2 } & \multicolumn{1}{c}{ G3 } & \multicolumn{1}{c}{ G4 } \\
\hline AST (U/l) & $50.83 \pm 2.48^{\mathrm{b}}$ & $101.00 \pm 2.93^{\mathrm{a}}$ & $48.16 \pm 1.97^{\mathrm{b}}$ & $39.50 \pm 4.08^{\mathrm{ab}}$ \\
\hline ALT (U/l) & $56.16 \pm 1.75^{\mathrm{b}}$ & $376.00 \pm 14.36^{\mathrm{a}}$ & $54.33 \pm 3.30^{\mathrm{b}}$ & $83.00 \pm 3.45^{\mathrm{ab}}$ \\
\hline Urea (mg/dl) & $21.58 \pm 1.12^{\mathrm{b}}$ & $65.68 \pm 2.15^{\mathrm{a}}$ & $35.31 \pm 1.43^{\mathrm{ab}}$ & $20.18 \pm 1.43^{\mathrm{b}}$ \\
\hline Albumin (gm/dl) & $4.50 \pm 0.33^{\mathrm{b}}$ & $2.25 \pm 0.60^{\mathrm{a}}$ & $4.55 \pm 0.48^{\mathrm{b}}$ & $4.8 \pm 0.52^{\mathrm{b}}$ \\
\hline Alkaline phosphatase (U/l) & $644.83 \pm 30.90^{\mathrm{b}}$ & $1148.50 \pm 40.10^{\mathrm{a}}$ & $533.16 \pm 69.61^{\mathrm{b}}$ & $1173.66 \pm$ \\
& & & & $106.04^{\mathrm{a}}$ \\
\hline Y-GT (U/l) & $182.98 \pm 4.50^{\mathrm{b}}$ & $437.93 \pm 9.45^{\mathrm{a}}$ & $168.00 \pm 5.27^{\mathrm{b}}$ & $206.83 \pm 2.41^{\mathrm{ab}}$ \\
\hline Catalase (U) & $97.58 \pm 1.51^{\mathrm{b}}$ & $44.48 \pm 1.84^{\mathrm{a}}$ & $103.86 \pm 2.80^{\mathrm{b}}$ & $76.95 \pm 2.16^{\mathrm{ab}}$ \\
\hline L-Malondialdehyde (nmol) & $12.46 \pm 0.63^{\mathrm{b}}$ & $67.95 \pm 2.78^{\mathrm{a}}$ & $15.53 \pm 0.77^{\mathrm{b}}$ & $36.10 \pm 3.21^{\mathrm{ab}}$ \\
\hline Superoxide Dismutase (U) & $5.70 \pm 0.21^{\mathrm{b}}$ & $1.48 \pm 0.15^{\mathrm{a}}$ & $5.67 \pm 0.37^{\mathrm{b}}$ & $3.58 \pm 0.21^{\mathrm{ab}}$ \\
\hline Glutathione (mmol) & $214.45 \pm 4.06^{\mathrm{b}}$ & $81.73 \pm 2.50^{\mathrm{a}}$ & $208.83 \pm 4.37^{\mathrm{b}}$ & $167.68 \pm 1.90^{\mathrm{ab}}$ \\
\hline $\begin{array}{l}\text { Data are presented as Mean } \pm \text { S.E. } \\
\text { S.E. : Standard Error }\end{array}$ & & & \\
a, b, c: Mean values with different superscript letters in the same row are significantly different at (P $\unlhd .05)$. & \\
G1: Normal control, G2: Hepatotoxic rats administrated DEN orally, G3: rats receive chitosan nanoparticles orally and G4: Hepatotoxic \\
rats treated with chitosan nanoparticles orally.
\end{tabular}




\section{DISCUSSION}

In the present study, we investigated the effects of chitosan-nanoparticles treatment on hepatotoxicity resulting from DEN administration. A significant increase in serum ALT and AST activities in DEN hepatotoxic rats has been attributed to hepatic structural damage because these enzymes are normally localized to the cytoplasm and released into the circulation after cellular damage has occurred (Singh et al., 2011). Injury to the hepatocytes alters their transport function and membrane permeability, leading to leakage of enzymes from the cells (Singh et al., 2011). Diethylnitrosamine (DEN) is known to induce damage in many enzymes involved in DNA repair and is normally used to induce liver cancer in experimental animal models (Bhosale et al., 2002). The activity of the enzymes including ALT and AST in the plasma can discern the index of liver injury. It is well known that chemical agents produce hepatic injury, causing both large increases in ALT and AST activity (Kedderis, 1996).

The normalization of plasma AST and ALT activities in chitosan and $\mathrm{CCl}_{4}$ treated animals indicates that chitosan may stabilize the cell membrane and prevent a leakage of intracellular enzymes into the blood (Jeon et al., 2003).

The present study suggested the decrease effect of chitosan nanoparticles on the activity of ALT, AST and ALP against DEN-induced changes in rats. The observed reduction in the levels of liver markers as a result of chitosan nanoparticles administration may result, in part, from the presence of antioxidant compounds that aid in reducing DEN-induced liver damage (Jeon et al., 2003). Similarity, Sandri et al., (2005) found that, chitosan nanoparticles treatment resulted in this effect because of the ability of chitosan nanoparticles to reduce oxidative stress and enhance the endogenous antioxidant defense status.

In the present study, the DEN treatment caused a decrease in albumin level compared with the control group. This was similar to the study of (Vandenberghe, 1996), who reported that, hypoalbuminemia may result from liver disorders, which are accompanied by a reduction in albumin synthesis. The study of Moshage et al., (1987) showed that, liver toxicity decrease serum albumin level. The results of the present study are in agreement with this finding and demonstrate the decreased functional ability of $\mathrm{CCl}_{4}$-injected rat livers (Natsume et al., 1999).

The present study suggested the ameliorative effect of CS on the level of albumin against DEN-induced changes in rats. Also, Aranaz et al., (2009) showed that, chitosan improves the plasma albumin level against $\mathrm{CCl}_{4}-$ induced hepatic damage in male Wistar rats. Moreover, Feldstein et al., (2005) reported that, chitosan improve albumin level in hepatotoxicity induced by DEN.

In the current study DEN administration to rats caused an increase in serum urea level. The elevation of serum urea level was came in accordance with the results obtained by (Ayla et al., 2011; Abou Seif 2012) who showed that, DEN caused a marked rise in serum urea level. Also Hemieda et al., (2016) showed that, treatment with $\mathrm{DEN} / \mathrm{CCl}_{4}$ caused elevated values in serum ALT, AST, ALP, Urea and total bilirubin with a marked decrease in total proteins and albumin concentration.

Treatment with chitosan to DEN induced hepatotoxic rats caused a significant decrease in urea concentration. These results accordance with, (Xie et al., 2001), who reported that, 
chitosan-nanoparticles possess strong effect on blood urea level in hepatotoxic rats.

The current data revealed a significant increase of liver MDA content with a reduction of GSH content and activities of the antioxidant enzymes SOD, GGT and CAT in DEN intoxicated rats when compared with normal control rats.

The significant increase of hepatic GSH level observed in the present study is in harmony with (Thirunavukkarasu et al., 2005), who also reported that increased GSH concentration in DEN-treated rat liver is probably due to the simultaneous observed two-fold increase in the activities of -GT and -glutamylcysteine synthetase ( -GCS), two main enzymes involved in GSH formation. The ubiquity of elevated GT levels in many rodent and human hepatic and extrahepatic carcinomas (Boateng et al., 2007) have led to the hypothesis that -GT provides a growth advantage to focal cells during carcinogenesis. A plausible hypothesis is that the advantage may be due to the role of -GT in the transport of GSH constituents, leading to increase in cellular GSH. The latter is required for proliferation and resistance (Komlosh et al., 2002). GSH plays a key role in the detoxification of the reactive toxic metabolites of $\mathrm{CCl}_{4}$; liver necrosis is initiated when reserves of GSH are markedly depleted (Komlosh et al., 2002).

Treatment with chitosan-nanoparticles to DEN induced hepatotoxic rats caused a significant decrease in liver MDA concentration. These results match with the study of (Zheng et al., 2012) who stated that, Phycocyanin has the ability to scavenge free radicals, decrease nitrite production, suppress inducible nitric oxide synthase expression, and inhibit liver microsomal lipid peroxidation. In addition, phycocyanin has been reported to inhibit proinflammatory cytokine formation, suppress cyclooxygeanase- 2 expression and decrease prostaglandin E2 production. Another constituent, $\beta$-carotene, has been reported to have antioxidant and anti-inflammatory activities (Katsuura et al., 2009).

Administration of chitosan-nanoparticles increased the activities of hepatic SOD and CAT in tissues and GSH concentration when compared to rats treated with DEN. We assumed that, the hepatoprotective effects of the tested chitosan-nanoparticles were due to their antioxidant properties and their ability to reduce lipid peroxidation. In this regard, (Wenshui et al., 2011) reported the hepatoprotective potential of chitosan-nanoparticles in acetaminopheninduced hepatotoxicity in mice and attributed this finding to the antioxidant effects of chitosannanoparticles and to its ability to potentiate the antioxidant system. In addition, Vinsova and Vavrikova (2008) reported that, chitosannanoparticles supplementation has reduced lipid peroxidation and increased activity of the antioxidant system in the liver of cadmiumintoxicated rats.

\section{CONCLUSION}

Chitosan-nanoparticles treatment ameliorates liver injuries induced by DEN by decreasing the values of biochemical parameters as ALT, AST, GGT, Alkaline Phosphatase,Urea and L-MDA and increasing the activities of antioxidant parameters as (CAT, GSH and SOD) and serum albumin that restore their alteration to near normal levels. Also increase in serum Albumin. From the obtained results, it could be concluded that, the hepatoprotective potential of chitosan nanoparticles as powerful natural agents and may be useful as an antioxidants in hepatotoxicity. 


\section{REFERENCES}

Abou Seif, H.S. (2012). Protective effects of rutin and hosperidin against Doxorubicininduced Nephrotoxicity. Beni-Sueif University J. Applied Sci. 1(2):1-18.

Aranaz, I.; Mengíbar, M.; Harris, R.; Paños, I.; Miralles, B.; Acosta, N.; Galed, G. and Heras, Á. (2009). Functional characterization of chitin and chitosan. Curr. Chem. Biol. 3, 203-230.

Ayla, S.; Seckin, I.; Tanriverdi, G.; Cengiz, M.; Eser, M.; Soner, B.C. and Oktem, G. (2011). Doxorubicin Induced Nephrotoxicity: Protective Effect of Nicotinamide. International Journal of Cell Biology. 1-9. doi:10.1155/2011/390238.

Beleta, J. and Gella, F.J. (1990). Método recomendado para la determinación en rutina de la concentración catalítica de la gglutamiltransferasa en suero sanguíneo humano, Quim. Clin., 9:58-61.

Beutler, E.; Duron, O. and Kelly, B.M. (1963). Improved method for the determination of blood glutathione, J. Lab. Clin. Med., 61:882-8.

Bhosale, P.; Motiwale, L.; Ingle, A.D.; Gadre, R.B. and Rao, K.V.K. (2002). Protective effect of Rhodotorula glutinis NCIM3353 on the development of hepatic preneoplastic lesions, Curr. Sci., 83: 303308.

Bleibel, W.; Kim, S.; D’Silva, K. and, Lemmer, E.R. (2007). Drug-induced liver injury. Review Article. Dig. Dis. Sci., 52: 24632471.

Boateng, J.; Verghese, M.; Shackelford, L.; Walker, L.T.; Khatiwada, J. and Ogutu, S. (2007). Selected fruits reduce azoxymethane (AOM)-induced aberrant crypt foci $(\mathrm{ACF})$ in Fisher 344 male rats. Food Chem. Toxicol. 45(5):725-732.

Deng, X.; Luyendyk, J.P.; Ganey, P.E. and Roth, R.A. (2009). Inflammatory stress and idiosyncratic hepatotoxicity: Hints from animal models. Pharmacol Rev 61: 262282.

Doumas, B.T.; Watson, W.A. and Biggs, H.G. (1997). Albumin standards and the measurement of serum albumin with bromcresol green. Clinica Chimica Acta. Volume 258, Issue 1, Pages 21-30.

El-Shahat, M.; El-Abd, S.; Alkafafy, M. and ElKhatib, G. (2012). Potential chemoprevention of diethylnitrosamine-induced hepatocarcinogenesis in rats: myrrh (Commiphora molmol) vs. turmeric (Curcuma longa). Acta Histochem. 114(5):421-8.

Esterbauer, H.; Cheeseman, K.H.; Danzani, M.U.; Poli, G. and Slater, T.F. (1982). Separation and characterization of the aldehyde products of $\mathrm{ADP} / \mathrm{Fe}+2 \mathrm{C}$ stimulated lipid peroxidation in rat liver microsomes. Biochem. J, (208): 129-140.

Feldstein, A.E.; Papouchado, B.G.; Angulo, P.; Sanderson, S.; Adams, L. and Gores GJ. (2005). Hepatic stellate cells and fibrosis progression in patients with nonalcoholic fatty liver disease. Clin Gastroenterol Hepatol. 3: 384 - 389.

Hemieda, F.A.E.; Serag,H.M.; El-Baz, E. and Ramadan, S.M.E. (2016). Therapeutic efficacy oflicorice and/or cisplatin against diethylnitrosamine and carbon tetrachloride-induced 
hepatocellularcarcinoma in rats. J Am Sci; 12(1):10-19]. (ISSN: 1545-1003).

Jeon, T.I.; Hwang, S.G.; Park, N.G.; Jung, Y.R.; Shin, S.I. and Choi, S.D. (2003). Antioxidative effect of chitosan on chronic carbon tetrachloride-induced hepatic injury in rats. Toxicology. 187:67e73.

Katsuura, S.; Imamura, T.; Bando, N. and Yamanishi, R. (2009). beta-Carotene and beta-cryptoxanthin but not lutein evoke redox and immune changes in RAW264 murine macrophages. Mol Nutr Food Res. 53:1396-405.

Kedderis, G.L. (1996). Biochemical basis of hepatocellular injury. Toxicol Pathol 24: 77-83.

Komlosh, A.; Volohonsky, G.; Porat, N.; Tuby, C.; Bluvshtein, E. and Steinberg, P. (2002). gamma-Glutamyl transpeptidase and glutathione biosynthesis in nontumorigenic and tumorigenic rat liver oval cell lines. Carcinogenesis. 23(4):671-678.

Liao, D.J.; Blanck, A.; Eneroth, P.; Gustafsson, J.A. and Hallstrom, I.P. (2001). Diethylnitrosamine causes pituitary damage, disturbs hormone levels, and reduces sexual dimorphism of certain liver functions in the rat. Environmental Health Perspectives, 109, 943-947.

Minami, M. and Yoshikawa, H. (1979). A simplified assay method of superoxide dismutase activity for clinical use. Clin. Chim. Acta 92:337-342.

Mohan, H. (2002). The liver, biliary tract and exocrine pancreas. Text book of pathology, Jaypee Brothers Medical Publishers (P) Ltd. New Delhi. 4:569-630.
Moshage, H.J.; Janssen, J.A.; Franssen, J.H.; Hafkenscheid, J.C. and Yap, S.H. (1987). Study of the molecular mechanism of decreased liver synthesis of albumin in inflammation .JClin Invest. 79(6):163541.

Murray, R.; Kaplan, A.; Rubaltelli, F.F. and Hammerman, (1984). Aminotransferases. C.Clin. Chem. The C.V. Mosby Co. St Louis. Toronto. Princeton, 1112-119.

Natsume, M.,; Tsuji, H.; Harada, A.; Akiyama, M.; Yano, T,; Ishikura, H.; Nakanishi, I.; Matsushima, K.; Kaneko, S. and Mukaida, N. (1999). Attenuated liver fibrosis and depressed serum albumin levels in carbon tetrachloride-treated IL-6-deficient mice. J Leukoc Biol. 66: 601 - 608.

Neimert-Andersson, T.; Ha"llgren, A.C.; Andersson, M.; Langeba“ck, J.; Zettergren, L. and Nilsen-Nygaard, J. (2011). Improved immune responses in mice using the novel chitosan adjuvant ViscoGel, with a Haemophilus influenzae type b glycoconjugate vaccine. Vaccine. 29:8965e73.

Nguyen, S.; Hisiger, S.; Jolicoeur, M.; Winnik, F.M. and Buschmann, M.D. (2009). Fractionation and Characterization of Chitosan by Analytical SEC and 1H NMR after Semi-Preparative SEC. Carbohydrate Polymers, 75, 636-645.

No, H.K.; Park, N.Y.; Lee, S.H. and Meyers, S.P. (2002). Antibacterial activity of chitosans and chitosan oligomers with different molecular weights. Int J Food Microbiol. 74:65e72.

Palton, C.J. and Crouch, S.R. (1977). Spectrophotometric and kinetics 
investigation of the Berthelot reaction for the determination of ammonia. J.Anal Chem. 49: 464-469.

Pradeep, K.; Mohan, C.V.; Gobianand, K. and Karthikeyan, S. (2007). Silymarin modulates the oxidant-antioxidant imbalance during diethylnitrosamine induced oxidative stress in rats. European Journal of Pharmacology, 560, 110-116.

Qi, L. and $\mathrm{Xu}, \mathrm{Z}$. (2006). In vivo antitumor activity of chitosan nanoparticles. Bioorg Med Chem Lett. 16:4243e5.

Rosalki, S.B.; Foo, A.Y.; Burlina, A,; Prellwitz, W.; Stieber, P.; Neumeier, D.; Klein, G.; Poppe, W.A. and Bodenmüller, H. (1993). Multicenter evaluation of Iso-ALP test kit for measurement of bone alkaline phosphatase activity in serum and plasma. Clin Chem. Apr;39(4):648-52.

Sandri, G.; Rossi, S.; Bonferoni, M.C.; Ferrari, F.; Zambito, Y.; Di Colo, G.; Caramella, C. (2005). Buccal penetration enhancement properties of $\mathrm{N}$-trimethyl chitosan: Influence of quaternization degree on absorption of a high molecular weight molecule. Int. J. Pharm. 297, 146-155.

Singh, A.; Bhat, T.K. and Sharma, O.P. (2011). Clinical Biochemistry of Hepatotoxicity. J Clinic Toxicol S4:001. doi:10.4172/21610495.S4-001

Singh, R.; Kumar, S.; Rana, A.C. and Sharma, N. (2012). Different models of hepatotoxicity and related liver diseases: A review. IRJP. 3(7):86-95.

Singh, A.; Bhat, T.K. and Sharma, O.P. (2011). Clinical Biochemistry of Hepatotoxicity. J Clinic Toxicol. S:4:1-19.
Sinha, A.K. (1972). Colorimetric assay of catalase. Analytical Biochemistry (47): 389.

Snedecor, G.W. and Cochran, W.G. (1969). Statistical Methods, 6th Ed. Iowa State University Press, Asmes, USA.

SPSS for windows, Version: 1119 September, 2001. Copyright SPSS Inc. 1989-2001. All rights reserved.

Sugiyama, K.P.; He, S.; Wada, S. and Saeki, (1999). Journal of Nutrition 129 (1999) 1361-1367.

Thirunavukkarasu, C.; Premkumar, K.; Jagadeeswaran, R. and Sakthisekaran, D. (2005). The inhibitory effect of sodium selenite on Nnitrosodiethylamine- induced and phenobarbital promoted liver tumourigenesis in rats based on the modulation of polyamine levels. Mol. Cell Biochem. 280(1-2):165-172.

Vandenberghe, J. (1996). Hepatotoxicology: Structure, function and toxicological pathology. In Toxicology: Principles and Applications Edited by Niesink, JM, Vries $\mathrm{J}$, Hollinger MA Vries J, Hollinger MA, 669-721.

Vinsova, J. and Vavrikova, E. (2008). Recent advances in drugs and prodrugs design of chitosan. Curr Pharmaco Des. 14, . 131126.

Vitaglione, P.; Morisco, F.; Caporaso, N. and Fogliano, V. (2004). Dietary antioxidant compounds and liver health. Crit Rev Food Sic Nutr. 2004; 44(7-8): 575-86.

Xie, W.; Xu, P. and Liu, Q. (2001). Antioxidant activity of watersoluble chitosan 
derivatives.Bioorg.Med.Chem.Lett. 11,1699-1701.

Wang, Q. et al. (2010). Norcantharindinassociated galactosylated chitosan nanoparticles for hepatocyte-targeted delivery. Nanomedicine: Nanotechnology, Biology and Medicine, 371-381.
Wenshui X, L. Ping, Z. Jiali and C. Jie. (2011). Biological activities of chitosan and chitooligosaccharides. Food Hydrocolloids. 25, 2011. 170- 79.

Zheng, D. et al. (2012). Galactosylated chitosan nanoparticles for hepatocyte-targeted delivery of oridonin. Int. J. Pharm. 436: 379- 386. 